\title{
Spiritual and religious beliefs: do they matter in the medication adherence behaviour of hypertensive patients?
}

Irene Kretchy ${ }^{1,2^{*}}$, Frances Owusu-Daaku ${ }^{1}$ and Samuel Danquah ${ }^{3}$

\begin{abstract}
Background: Medication non-adherence is often a predominant problem in the management of hypertension and other chronic conditions. In explaining health behaviours, social determinants like spirituality and religiosity are increasingly identified to impact health and treatment. Although a number of researchers have found spirituality and religiosity to be primary resources among persons dealing with chronic disability and illness, studies relating this specifically to medication adherence have been limited.
\end{abstract}

Methods: Our study sought to examine the interrelationship between spirituality/ religiosity and medication adherence among 400 hypertensive patients 18 years old and above. Spiritual Perspective Scale, Duke Religion Index, and the Morisky Medication Adherence Scale were used to determine spirituality, religiosity and medication adherence respectively.

Results: The majority (93.25\%) of patients poorly adhered to their medications. While high spiritual and religious beliefs formed core components of the lifestyles of patients, spirituality $(p=0.018)$ and not religiosity $(p=0.474)$ related directly with medication non-adherence. Likewise, after controlling for demography and other medical co-morbidities, patients with high spirituality were 2.68 times more likely to be poorly adherent than patients who place lower emphasis on the association between spirituality and health.

Conclusion: Our study suggests that while spirituality/ religiosity was dominant among hypertensive patients, these spiritual attachments of patients with a supreme being potentially increased their trust in the expectation of divine healing instead of adhering adequately with their anti-hypertensive medications.

Keywords: Spirituality, Religiosity, Medication non-adherence, Co-morbidity, Ghana

\section{Background}

Medication adherence is a major health behaviour noted to improve the quality of life of patients. However, nonadherence is often a predominant problem in the management of hypertension and other chronic conditions [1]. Even though the World Health Organization has estimated the non-adherence rate to pharmacotherapy for hypertension to be approximately 50\%, Ghana, a

\footnotetext{
* Correspondence: iakretchy@yahoo.com

'Department of Clinical and Social Pharmacy, Faculty of Pharmacy and Pharmaceutical Sciences, Kwame Nkrumah University of Science and Technology, Kumasi, Ghana

${ }^{2}$ Department of Pharmacy Practice and Clinical Pharmacy, University of Ghana School of Pharmacy, College of Health Sciences, Accra, Ghana Full list of author information is available at the end of the article
}

developing country has recorded a very high nonadherence rate of $93 \%$ [2].

Contrary to the availability of treatment for hypertension, most patients do not follow recommendations by their healthcare professionals and this results in poor hypertension management [3]. Most patients require one or more antihypertensive medications to achieve optimal blood pressure and this has been associated with an increased cost of hypertension management in Ghana [2]. A significant worsening of disease, treatment failures, increased hospitalizations, death, and increased health care costs remain the main consequences of medication non-adherence [4]. Patients with untreated and uncontrolled hypertension are at an increased risk of developing stroke, heart attack, and kidney or heart 
failure, which can eventually lead to death. Inadequate control of hypertension has also been associated with cognitive decline in elderly patients [5] resulting in both social and financial burdens [6].

In explaining health behaviours, social determinants like spirituality and religiosity are increasingly identified as impacting health and treatment. Systematically, spirituality and religiosity have been introduced into the medical field implying a growing interest in the possible perceived health benefits connected with having a spiritual belief and following a religious lifestyle [7].

Specifically, spirituality relates to feelings or experiences of reverence, peace, or attachment with a Supreme Being and is usually identified as that which gives a transcendent meaning to life where God takes the initiative in this typical divine-human relationship [8]. Notwithstanding varied descriptions of spirituality, the core concepts are the same [9]. It may well comprise the internal, personal, and emotional expression of the revered and is evaluated using spiritual wellbeing, peace, and comfort derived from faith, and spiritual coping [8].

Religiosity relates more with cultural and social norms and refers to an outward prescribed system of beliefs and guidelines of conduct [10]. It is generally explained in a behavioural context where rituals and other related symbolic activities (e.g., meditations, prayers, fasting, reading religious scripts, attendance at services, etc.) are practised by individuals according to their specific beliefs and modes of social organization $[9,11]$. These activities have been noted to strengthen the faith of people and assist them with decision making in health-related practices.

Formerly, spirituality and religiosity were examined as a one-dimensional construct, yet, various researchers have attempted to categorize and distinguish particular aspects of the two constructs [12]. Nevertheless, religion is generally inter-related with spirituality since the former provides a structured environment for spiritual exploration and practices in life and the two constructs have been conceptualized to influence the development of each other [13]. For example, religious practices encourage spiritual growth and spiritual activities are often an important aspect of religious participation [9,14].

Although there are still deliberations on possible association of spirituality/ religiosity with health and weaknesses in the definition and measurement of the constructs, attempts have been made to operationalize and conceptualize spirituality and religiosity to relate with health outcomes as well as its impact on the social domain [9,15-18].

Various studies have explored the influence of spirituality/religiosity on positive health behaviours among college students, in the field of gerontology, in heart failure, mental health outcomes, blood pressures, cancer and mortality rates [19-25] with other researchers not observing this trend [26,27].

The 2010 national population census indicated that over $90 \%$ of Ghanaians identified with a form of religion, yet, there is paucity of information regarding the spiritual/ religious inclination and the health seeking behaviours of Ghanaians. Additionally, a number of researchers have found spirituality and religiosity to be a primary resource among persons dealing with chronic disability and illness however, studies relating this specifically to medication adherence have been limited. Nevertheless, addressing spiritual and religious needs of patients could enhance their medication adherence behaviour and thus, improve their health outcome [28].

In view of this, the study postulated that: Explored dimensions of spirituality/religiosity will significantly influence the adherence behaviour of hypertensive patients with the expectation that high scores of spiritual beliefs and religious practices will positively influence the decision by patients to adhere to their antihypertensive medications.

\section{Methods}

\section{Study setting}

This is a two-centre study, involving the two major tertiary hospitals in Ghana - Korle-Bu Teaching Hospital (KBTH), Accra and Komfo Anokye Teaching Hospital (KATH), Kumasi. The KBTH, the premier and largest teaching hospital, is located in the Accra District of Greater Accra Region. Being the only tertiary hospital in the southern part of Ghana, KBTH serves the people of Accra and surrounding urban towns located southwards. Komfo Anokye Teaching Hospital, the second largest hospital in the country, is another tertiary health institution located in Kumasi, the Regional Capital of Ashanti Region. It serves as the main referral facility for the northern (non-coastal) parts of Ghana. In selecting these two hospitals, the rationale was to recruit research participants with diverse spiritual/ religious behaviours who would fairly represent both southern and northern parts of Ghana to allow for generalization of results.

\section{Study participants}

After obtaining informed consent from 200 recruited study participants from each study site, a quantitative approach was employed in this hospital-based crosssectional study between May and October, 2012. Hypertensive patients were identified through the patient records folders and this information was substantiated by the patients themselves. Researcher-administered structured questionnaires were used to obtain information on demographic characteristics, spirituality, religiosity, and medication adherence. The participants included in this study were male and female Ghanaian patients who were 
18 years and above, diagnosed with hypertension only or hypertension with other health conditions. Patients should have reported being prescribed at least one antihypertensive medication not less than six months prior to the time of data collection. Hypertensive patients who were not on any form of prescribed anti-hypertensive medications, as well as patients who were unable to respond to or understand the English language, in patients, and the incapacitated were excluded from this study.

\section{Measures}

Spirituality, religiosity, and medication adherence were the variables measured in this study. The ten-item Spiritual Perspective Scale (SPS) is designed to measure perceptions of the extent to which participants hold certain spiritual views and engage in spiritually-related interactions. Each of the 10 items uses a 6-point Likert-type scale ranging from strongly disagree to strongly agree is scored using the mean. Scores above the mean indicate high spiritual involvement and those below the mean value indicate the reverse. The SPS has been used successfully in a wide variety of adult populations. Using the Cronbach's alpha, reliability has consistently rated above 0.90 and average inter-item correlations range from 0.54 to 0.60 across adult groups [29].

Religious beliefs and religious involvement was measured with the Duke Religion Index (DUREL), a two-item measure assessing two domains of religiosity: Organized Religious Activity (ORA), i.e., ("How often do you attend church or religious meetings?"), and Non-organized Religious Activity (NORA), i.e., ("How often do you spend time in private religious activities, such as prayer, meditation, or Bible study?"). Responses range from 1 ("more than once a week") to 6 ("never") for ORA and 1 ("more than once a day") to 6 ("rarely or never") for NORA. Scoring is based on a separate regression model for each item. DUREL has been validated in health research with Cronbach's alpha values ranging from 0.75 to 0.88 [30].

Medication adherence was assessed with the Morisky Medication Adherence Scale (MMAS). It has 8 items of that respondents score from zero to eight and enables categorization as low adherence $(<6)$, medium adherence $(6-<8)$, and high adherence (8). Patients who scored low and moderate were grouped as poorly adherent to allow for statistical analysis [31]. The MMAS reliability measure was 0.83 for a study on hypertensive outpatients [32].

\section{Statistical analysis}

Data for this study were analyzed using the Statistical Package for Social Sciences (SPSS) version 20. Descriptive statistics were used for frequency counts and percentages of characteristics of participants and study tools (SPS, DUREL and MMAS). Chi-square test and
Table 1 Sample characteristics

\begin{tabular}{lll}
\hline Variable & Mean & Standard deviation \\
\hline Sex & 1.63 & 0.48 \\
Age & 57.10 & 10.87 \\
Co-morbidities & 1.58 & 0.49 \\
\hline
\end{tabular}

logistic regression were used for evaluating relationship spirituality/ religiosity and medication adherence.

\section{Ethical considerations}

All procedures for the study were endorsed by the Institutional Review Boards at Noguchi Memorial Institute for Medical Research, Accra and Committee of Human Research, Publications and Ethics, Kumasi with the respective ethical approval codes NMIMR-IRB CPN 044/10-11 and CHRPE/AP/022/12. Written permission was sought from Prof. Pamela Reed and Dr. Donald Morisky to enable the research team use the SPS and MASS, respectively.

\section{Results}

Sample and subscale characteristics

A summary of the socio-demographic characteristics (mean and standard deviation) of the study population in relation to sex, age, and co-morbidities are presented in Table 1 . The majority of patients were female $(62.75 \%)$, married (63.50\%), and between the ages of 50 and 59 years $(32.50 \%)$ who had attained a minimum of secondary school education (54.25\%), were Christians (90.0\%) and had been diagnosed with hypertension for less than or equal to 10 years $(79.50 \%)$. Forty two percent $(42 \%)$ of the patients had co-morbidities and diabetes accounted for $60 \%$ of these. The various scales used in this study (SPS, DUREL and MMAS) showed good reliability coefficients (Table 2).

\section{Medication adherence}

Medication adherence behaviour of patients was assessed using MMAS. Table 3 shows that ninety-three percent of participants poorly adhered to their antihypertensive medications.

\section{Spirituality and religiosity}

Very high proportions of patients frequently engaged in spiritually related activities, which formed significant aspects of their daily lives (Table 4). Similarly, Table 5 indicates that over $80 \%$ of the patients regularly (once or

Table 2 Characteristics of sub scales

\begin{tabular}{lll}
\hline Scale & Number of items & Reliability coefficient \\
\hline SPS & 10 & 0.878 \\
DUREL & 2 & 0.513 \\
MMAS & 8 & 0.793 \\
\hline
\end{tabular}


Table 3 Frequency distribution for medication adherence

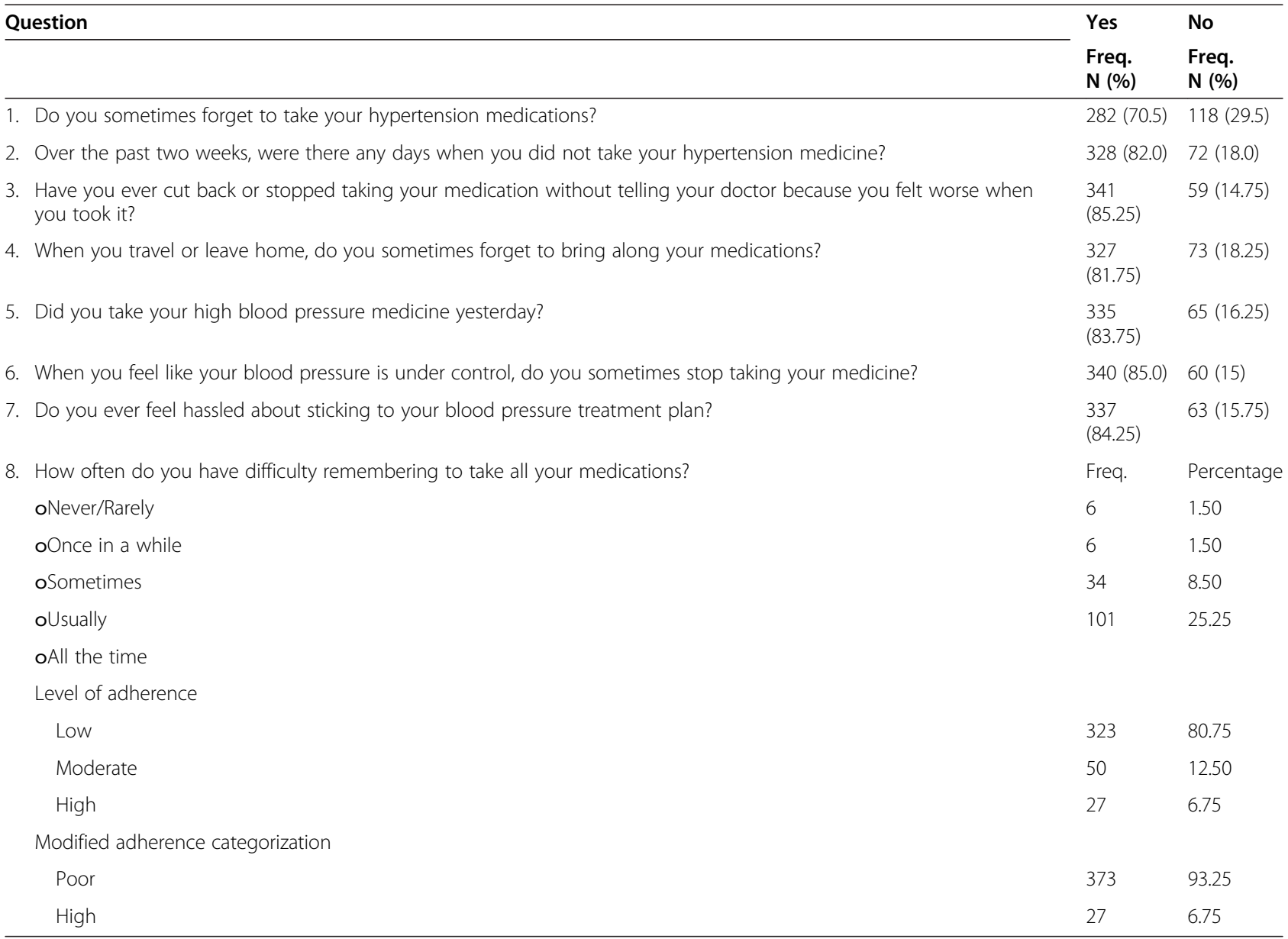

\section{Table 4 Frequency distribution for SPS}

\begin{tabular}{|c|c|c|c|c|c|}
\hline Statement & $\begin{array}{l}\text { Not } \\
\text { at all }\end{array}$ & $\begin{array}{l}\text { About once } \\
\text { a year }\end{array}$ & $\begin{array}{l}\text { About once } \\
\text { a month }\end{array}$ & $\begin{array}{l}\text { About once } \\
\text { a week }\end{array}$ & $\begin{array}{l}\text { About } \\
\text { once a day }\end{array}$ \\
\hline 1. In talking with family and friends, how often do you mention spiritual matters & 32 & 10 & 39 & 121 & 198 \\
\hline $\begin{array}{l}\text { 2. How often do you share with others the problems and joys of living } \\
\text { according to your spiritual beliefs }\end{array}$ & 12 & 13 & 31 & 144 & 200 \\
\hline 3. How often do you read spiritually-related material & 45 & 14 & 11 & 89 & 241 \\
\hline 4. How often do you engage in private prayer and meditation & 6 & 8 & 14 & 57 & 315 \\
\hline 5. Forgiveness is an important part of my spirituality & 6 & 7 & 12 & 52 & 323 \\
\hline 6. I seek spiritual guidance in making decisions in my everyday life & 7 & 7 & 21 & 57 & 308 \\
\hline 7. My spirituality is a significant part of my life & 8 & 6 & 8 & 59 & 319 \\
\hline $\begin{array}{l}\text { 8. I frequently feel very close to God or 'a higher power' in prayer, during public } \\
\text { worship or at important moments in my life }\end{array}$ & 8 & 12 & 23 & 43 & 314 \\
\hline 9. My spiritual views have had an influence upon my life & 12 & 4 & 10 & 84 & 290 \\
\hline $\begin{array}{l}\text { 10. My spirituality is especially important to me because it answers many } \\
\text { questions about the meaning of life }\end{array}$ & 6 & 4 & 10 & 53 & 327 \\
\hline
\end{tabular}


Table 5 Distribution of organised religious activity by patients

\begin{tabular}{lllllll}
\hline Item & $\begin{array}{l}\text { More } \\
\text { than } \\
\text { once/ } \\
\text { week }\end{array}$ & $\begin{array}{l}\text { Once } \\
\text { a } \\
\text { week }\end{array}$ & $\begin{array}{l}\text { A few } \\
\text { times } \\
\text { a } \\
\text { month }\end{array}$ & $\begin{array}{l}\text { A few } \\
\text { times } \\
\text { a } \\
\text { year }\end{array}$ & $\begin{array}{l}\text { Once a } \\
\text { year } \\
\text { or }\end{array}$ & less \\
\hline $\begin{array}{l}\text { How often do you } \\
\text { attend church or }\end{array}$ & 178 & 176 & 17 & 10 & 8 & 11 \\
$\begin{array}{l}\text { other religious } \\
\text { meetings? }\end{array}$ & & & & & & \\
\hline
\end{tabular}

more than once a week) attended church or other religious meetings. The majority (> 50\%) of patients frequently (daily or more than once a day) engaged in non-organized religious activities like prayer, meditation, or Bible study (Table 6).

\section{Spirituality/ religiosity and medication non-adherence}

The relationship between spirituality, religiosity, and medication non-adherence was measured with a chisquare test and logistic regression. After adjusting for demographic characteristics and co-morbid health conditions, spirituality, but not religiosity, was associated with medication non-adherence, although patients exhibited high levels of both spirituality and religiosity at $\mathrm{p}<0.05$ (Tables 7 and 8). Additionally, a logistic regression analysis conducted to determine whether the presence of comorbidities considerably influenced the medication adherence of respondents revealed no significant association $[(\mathrm{OR})=1.31$ (95\% CI $0.60-2.86), p=0.504]$.

\section{Discussion}

The study found that poor adherence to antihypertensive medication regimen was high, occurring in 93.25\% of respondents. This corroborates findings from a previous study by Buabeng et al. (2004) [2] that observed non-adherence rates by hypertensive patients to be essentially the same (93\%), but is double the worldwide estimate of $50 \%$ put forward by the WHO. Although associations were not measured, it is possible to

Table 6 Distribution of non-organised religious activity by patients

\begin{tabular}{lllllll}
\hline Item & $\begin{array}{l}\text { More } \\
\text { than } \\
\text { once/day }\end{array}$ & Daily & $\begin{array}{l}\text { Two/more } \\
\text { times/week }\end{array}$ & $\begin{array}{l}\text { Once } \\
\text { a } \\
\text { week }\end{array}$ & $\begin{array}{l}\text { A few } \\
\text { times } \\
\text { a } \\
\text { month }\end{array}$ & $\begin{array}{l}\text { Rarely } \\
\text { or } \\
\text { Never }\end{array}$ \\
\hline $\begin{array}{l}\text { How often } \\
\text { do you } \\
\text { spend time }\end{array}$ & 135 & 113 & 66 & 59 & 10 & 17 \\
in private \\
religious \\
activities, \\
such as \\
prayer, \\
meditation
\end{tabular}

Table 7 Relationship between spirituality/religiosity and medication non-adherence

\begin{tabular}{|c|c|c|c|c|c|c|}
\hline \multirow{2}{*}{$\begin{array}{l}\text { Medication } \\
\text { adherence }\end{array}$} & \multicolumn{2}{|c|}{ Spirituality (\%) } & \multicolumn{2}{|c|}{ ORA (\%) } & \multicolumn{2}{|c|}{ NORA (\%) } \\
\hline & Low & High & Low & High & Low & High \\
\hline High & 51.85 & 48.15 & 33.33 & 66.67 & 29.63 & 70.37 \\
\hline Poor & 30.03 & 60.07 & 45.31 & 54.69 & 34.05 & 65.95 \\
\hline$x^{2}$ & 5.558 & & 1.494 & & 0.222 & \\
\hline$p$ value & 0.018 & & 0.474 & & 0.895 & \\
\hline
\end{tabular}

$p<0.05$.

project that such a great difference in non-adherence could negatively impact health outcomes and contribute considerably to worsening of disease, increased health care costs, and eventually death [4].

The study has also demonstrated that a major proportion of hypertensive patients exhibited a high sense of spiritual belief and followed consistent religious lifestyles. Of the 400 hypertensive patients, about $90 \%$ were Christians, $5 \%$ were Muslims, while $1 \%$ identified with the Traditional religion. This trend is comparable to findings from the national population census in 2010, in which approximately $71 \%, 18 \%$ and $5 \%$ of the Ghanaian population were Christians, Muslims, and Traditionalists respectively. Similarly, a great proportion of patients regularly (once or more than once a week) attended church or other religious meetings, and a major percentage of the patients frequently (daily or more than once a day) engaged in non-organized religious activities like prayer, meditation, or Bible study. It was also apparent from the Spiritual Perspective Scale that very high proportions of patients frequently engaged in spiritually related activities. These spiritual activities formed noteworthy aspects of their daily lives. With regard to establishing a relationship between spirituality/ religiosity and anti-hypertensive medication adherence, we observed that while spirituality significantly influenced non-adherence, organized and non-organized religiosity did not. Likewise, after controlling for demography and co-morbidities, patients with high spirituality were 2.68 times more likely to be poorly adherent than patients who place lower emphasis on the association between spirituality and health.

This means that the lower likelihood of adhering to treatment was a result of high spiritual beliefs of patients

Table 8 Logistic regression model for spirituality, organised and non-organised religiosity in relation to medication non-adherence behaviour

\begin{tabular}{llll}
\hline Variable & $\begin{array}{l}\text { Odds } \\
\text { ratio }\end{array}$ & $\begin{array}{l}\mathbf{9 5 \%} \text { confidence } \\
\text { interval }\end{array}$ & $\begin{array}{l}\boldsymbol{p} \\
\text { value }\end{array}$ \\
\hline $\begin{array}{l}\text { High spirituality (Ref: Low } \\
\text { spirituality) }\end{array}$ & 2.68 & $1.20-5.96$ & 0.016 \\
$\begin{array}{l}\text { High ORA (Ref: Low ORA) } \\
\text { High NORA (Ref: Low NORA) }\end{array}$ & 0.65 & $0.35-1.21$ & 0.176 \\
\hline
\end{tabular}


and not behavioural religious characteristics. These outcomes directly contradict our postulation that 'spirituality/religiosity will significantly influence medication adherence positively'. The results also contradict findings by Simoni, Frick, and Huang (2006) [33] and Raghavan et al. (2013) [34] whose studies have shown a positive impact of spirituality/ religiosity on medication adherence. It is worth noting that these studies were not conducted with a sub-Saharan African population. Spirituality/religiosity is an important component of the cultural beliefs of Africans, but to date there is little information examining how sub-Saharan Africans, and specifically Ghanaian adults with hypertension, relate spirituality/religiosity to medication adherence. For example, in examining barriers to antiretroviral therapy (ART) adherence in Uganda, Wanyama et al. (2007) [35] noted that some patients discontinued ART because of a belief in spiritual healing. In our study, we have demonstrated that although hypertensive patients exhibited high spiritual beliefs and engaged in frequent religious activities, spirituality and not religiosity influenced medication non-adherence. Thus, beliefs and practices can be treated as separate domains. These results seem to suggest that hypertensive patients related more to experiences of peace, and reverence or attachment with a Supreme Being [36]. Potentially, they may place more trust in the divine expectation of healing and not on conventional orthodox medications. The patients may tend to believe in God or a Supreme Being for possible healing, knowing the chronic and in most cases incurable nature of hypertension [35]. This further suggests that some patients would risk not taking their medications while anticipating divine healing outcomes. The observation is in line with spiritual causal theories strongly underlining chronic conditions in Ghana [37]. In a related study on medication adherence among persons with mental illness in Ghana, a similar trend was observed. Patients and their families sought spiritual interventions for their mental illness because they perceived the conventional antipsychotic medications failed to achieve a complete cure [38].

It is thus imperative for health professionals to be holistic in their approach to healthcare by taking into consideration the importance of the spirituality of their patients while providing care.

In spite of the above findings, the study was limited in the fact that the main target participants were derived from tertiary hospitals only, yet, hypertensive patients in Ghana are managed in various hospitals, not only the two tertiary hospitals used for this study.

\section{Conclusion}

This study anticipated filling the knowledge gap in relation to establishing an association between spirituality/ religiosity and medication adherence among hypertensive patients in Ghana and by extension sub-Saharan Africans. The study outcome has demonstrated that while high spiritual and religious beliefs form core components of the lifestyles of hypertensive patients, spirituality, not religiosity, related directly to medication non-adherence, a highly prevalent risk behaviour of the patients. Thus, religiosity ought not to be equated to spirituality. Our study suggests that the reverence, experiences, and attachment of patients with a supreme being may potentially increase their trust or expectation of divine healing to the detriment of reliance on conventional orthodox anti-hypertensive medications. Thus, the study suggests that when treating patients or implementing medication non-adherence intervention programmes, considerable emphasis should be on the dynamics of the effects of spirituality, not necessarily religiosity.

\section{Competing interests}

The authors declare that they have no competing interests.

\section{Authors' contributions}

IK was involved with research concept, data collection, data analysis, interpretation of results, and writing of manuscript. FO contributed to research concept, study design and review of manuscript. SD participated in research concept and study design. All authors reviewed and approved the final manuscript.

\section{Acknowledgements}

We thank Prof. Pamela Reed and Dr. Donald Morisky for the study tools. This research was partially funded by the African Doctoral Dissertation Research Fellowship offered by the African Population and Health Research Center (APHRC) in partnership with the International Development Research Centre (IDRC) as well as the University of Ghana Faculty Development Grant by Office of Research, Innovation and Development (ORID).

\section{Author details}

${ }^{1}$ Department of Clinical and Social Pharmacy, Faculty of Pharmacy and Pharmaceutical Sciences, Kwame Nkrumah University of Science and Technology, Kumasi, Ghana. ${ }^{2}$ Department of Pharmacy Practice and Clinical Pharmacy, University of Ghana School of Pharmacy, College of Health Sciences, Accra, Ghana. ${ }^{3}$ Department of Psychology, University of Ghana, Legon, Ghana.

Received: 21 May 2013 Accepted: 15 October 2013 Published: 18 October 2013

\section{References}

1. Ho MP, Bryson CL, Rumsfeld JS: Medication adherence: its importance in cardiovascular outcomes. Circulation 2009, 119:3028-3035.

2. Buabeng $\mathrm{KO}$, Matowe L, Plange-Rhule J: Unaffordable drug prices: the major cause of non-compliance with hypertension medication in Ghana. J Pharm Pharmaceut Sci 2004, 7(3):350-352.

3. Agyemang C, Bruijnzeels MA, Owusu-Dabo E: Factors associated with hypertension awareness, treatment, and control in Ghana, west Africa. J Hum Hypertens 2006, 20:67-71.

4. Osterberg L, Blaschke T: Adherence to medication. N Engl J Med 2005 353:487-497.

5. Gombojav B, Yi SW, Sull JW, Nam CM, Ohrr H: Combined effects of cognitive impairment and hypertension on total mortality in elderly people: the kangwha cohort study. Gerontology 2011, 57(6):490-496.

6. Redwood H: Hypertension, society, and public policy. Eur Heart $J$ 2007, 9:B13-B18. 
7. Penman J, Oliver M, Harrington A: Spirituality and spiritual engagement as perceived by palliative care clients and caregivers. Aust J Adv Nurs 2009, 26(4):29-35

8. Kudel I, Cotton S, Szaflarski M, Holmes WC, Tsevat J: Spirituality and religiosity in patients with HIV: a test and expansion of a model. Ann Behav Med 2011, 41(1):92-103.

9. Miller WR, Thoresen CE: Spirituality, religion, and health. Am Psychol 2003, 58:24-35.

10. Mohr WK: Spiritual issues in psychiatric care. Perspect Psychiatr Care 2006, 42:174-183.

11. Koenig HG, McCullough ME, Larson DB: Handbook of religion and health. Oxford: Oxford University Press; 2001.

12. Pearce MJ, Little TD, Perez JE: Religiousness and depressive symptoms among adolescents. J Clin Child Adolesc Psychol 2003, 32(2):267-276.

13. McDade R: A mixed method study of spirituality and the influence on TB medication adherence. In Proceedings of the sixth annual college of education research conference: 2007: urban and international education section. Edited by Nielsen SM, Plakhotnik MS. Miami, Florida: International University:54-59.

14. Armstrong TD, Crowther MR: Spirituality among older African-Americans J Adult Dev 2002, 9(1):3-12

15. Campbell JD, Yoon DP, Johnstone B: Determining relationships between physical health and spiritual experience, religious practices, and congregational support in a heterogeneous medical sample. J Relig Health 2010, 49:3-17.

16. Hackney CL, Sanders GS: Religiosity and mental health: a meta-analysis of recent studies. J Sci Study Relig 2003, 42:43-55.

17. Hall DE, Meador KG, Koenig HG: Measuring religiousness in health research: review and critique. J Relig Health 2008, 47(2):134-163.

18. Levin J: "And let us make us a name": reflections on the future of the religion and health field. J Relig Health 2009, 48:125-145

19. Buck AC, Williams DR, Musick MA, Sternthal MJ: An examination of the relationship between multiple dimensions of religiosity, blood pressure, and hypertension. Soc Sci Med 2009, 68(2):314-322.

20. Gillum RF, Ingram DD: Frequency of attendance at religious services, hypertension, and blood pressure: the third national health and nutrition examination survey. Psychosom Med 2006, 68(3):382-385.

21. Hummer RA, Ellison CG, Rogers RG, Moulton BE, Romero RR: Religious involvement and adult mortality in the United States: review and perspective. South Med J 2004, 97:1223-1230.

22. Koenig HG: Religion, spirituality, and medicine: research findings and implications for clinical practice. South Med J 2004, 97:1194-1200.

23. Clay KS, Talley C, Young KB: Exploring spiritual well-being among survivors of colorectal and lung cancer. J Relig Spiritual Soc Work 2010, 29(1):14-32.

24. Powell LH, Shahabi L, Thoresen CE: Religion and spirituality. Linkages to physical health. Am Psychol 2003, 58(1):36-52.

25. Riegel B, Moser DK, Anker SD, Appel L, Dunbar SB, et al: State of the science: promoting self-care in persons with heart failure: a scientific statement from the American heart association. Circulation 2009, 120(12):1141-1163.

26. Westlake C, Dracup K, Creaser J, Livingston N, Heywood JT, et al: Correlates of health-related quality of life in patients with heart failure. Heart Lung 2002, 31(2):85-93.

27. Beery TA, Baas LS, Fowler C, Allen G: Spirituality in persons with heartfailure. J Holist Nurs 2002, 20(1):5-25.

28. Erah PO, Arute JE: Adherence of HIV/AIDS patients to antiretrovira therapy in a tertiary health facility in Benin City. Afr J Pharm Pharmacol 2008, 2(7):145-152

29. Jesse DE, Reed RG: Effects of spirituality and psychosocial well-being on health risk behaviors in Appalachian pregnant women. J Obstet, Gynecolo, and Neonatal Nurs 2004, 33:739-747.

30. Fetzer Institute, National Institute on Aging Working Group: Multidimensional measurement of religiousness/ spirituality for use in health research. Kalamazoo: Fetzer Institute; 2003.

31. Ross S, Walker A, MacLeod MJ: Patient compliance in hypertension: role of illness perceptions and treatment beliefs. J Hum Hypertens 2004, 18:607-613.

32. Morisky DE, Ang A, Krousel-Wood M, Ward HJ: Predictive validity of a medication adherence measure in an outpatient setting. $J$ Clin Hypertens 2008, 10(5):348-354

33. Simoni JM, Frick PA, Huang B: A longitudinal evaluation of a social support model of medication adherence among HIV-positive men and women on antiretroviral therapy. Health Psychol 2006, 25(1):74-81.
34. Raghavan R, Ferlic-Stark L, Clarke C, Rungta M, Goodgame R: The role of patient religiosity in the evaluation and treatment outcomes for chronic HCV Infection. J Rel Health 2013, 52:79-90.

35. Wanyama J, Castelnuovo B, Wandera B, Mwebaze P, Kambugu A, Bandsberg DR, et al: Belief in divine healing can be a barrier to antiretroviral therapy adherence in Uganda. AIDS 2007, 21(11):1486-1487.

36. Johnstone B, Franklin KL, Yoon DP, Burris J, Shigaki C: Relationships among religiousness, spirituality, and health for individuals with stroke. J Clin Psychol Med Settings 2008, 15:308-313.

37. de-Graft Aikins A, Anum A, Agyemang C, Addo J, Ogedegbe O: Lay representations of chronic diseases in Ghana: implications for primary prevention. Ghana Med J 2012, 46(2):59-68.

38. Read U: "I want the one that will heal me completely so it won't come back again": the limits of antipsychotic medication in rural Ghana. Transcult Psychiatry 2012, 49(3-4):438-460.

doi:10.1186/1751-0759-7-15

Cite this article as: Kretchy et al:: Spiritual and religious beliefs: do they matter in the medication adherence behaviour of hypertensive patients? BioPsychoSocial Medicine 2013 7:15

\section{Submit your next manuscript to BioMed Central and take full advantage of:}

- Convenient online submission

- Thorough peer review

- No space constraints or color figure charges

- Immediate publication on acceptance

- Inclusion in PubMed, CAS, Scopus and Google Scholar

- Research which is freely available for redistribution

Submit your manuscript at www.biomedcentral.com/submit
C Biomed Central 